\title{
Effective Removal of Estrogens from Drinking Water and Wastewater by Adsorption Technology
}

\author{
Jens Hartmann • Reinhard Beyer • Stephan Harm
}

Received: 13 November 2013 / Accepted: 18 December 2013 / Published online: 24 April 2014

(C) Springer International Publishing Switzerland 2014

\begin{abstract}
Estrogens, either of natural or synthetic origin, are well known for their impact on the reproductive system of both humans and animals. With conventional wastewater treatment it is not possible to remove estrogens efficiently. Subsequently, estrogen contaminated water enters the hydrological cycle and leads to an accumulation in surface water, groundwater as well as in drinking water. Therefore, new methods have to be introduced in order to face the increasing contamination of wastewater. Aim of this in vitro study was the characterization of adsorbents which are used in the field of extracorporeal blood purification for their potential use in wastewater treatment. For the conducted batch experiments, we used activated carbon as well as hydrophobic resins and anion exchangers to characterize their adsorption kinetics and capacity for estrogen. 17 $\beta$-Estradiol (E2), as a model substance for the natural estrogens (E1E4), as well as synthetic $17 \alpha$-ethinylestradiol (EE2) were added to both distilled water and water taken from the draining channel of a local purification plant. Adsorbents were added at a concentration of $1 \mathrm{~g} / \mathrm{L}$ water. Samples were taken at $0,15,30,60$ and $120 \mathrm{~min}$ and analyzed by a newly developed simplified HPLC-based method. Our results show that hydrophobic resins based on Polystyrene-Divinylbenzene (PS-DVB) are promising materials for the effective removal of estrogens from wastewater. Adsorption technology could be an efficient technique to upgrade sewage treatment plants for the removal of estrogens from the hydrological cycle.
\end{abstract}

Keywords Adsorption - Estrogen - Water purification · Endocrine disruptive compounds

\section{Introduction}

One of the most pervasive problems afflicting people throughout the world is inadequate access to clean water and sanitation. Problems with water are expected to grow worse in the

J. Hartmann $(\triangle) \cdot$ R. Beyer $\cdot$ S. Harm

Department for Health Sciences and Biomedicine, Danube University Krems, Dr.-Karl-Dorrek Str. 30, $3500 \mathrm{Krems}$, Austria

e-mail: jens.hartmann@donau-uni.ac.at

R. Beyer

e-mail: reinhardbeyer@yahoo.de

S. Harm

e-mail: Stephan.harm@donau-uni.ac.at 
coming decades, with water scarcity occurring globally, even in regions currently considered water-rich. Addressing these problems calls out for a tremendous amount of research to be conducted to identify robust new methods of purifying water at lower cost and with less energy, while at the same time minimizing the use of chemicals and impact on the environment (Shannon et al. 2008). Pharmaceutical residues in water are frequently analysed and discussed in connection with sewage treatment, ecotoxicity, and natural and drinking water quality. If the drugs are not degraded or eliminated during sewage treatment, in soil or in other environmental compartments, they will reach surface water and groundwater, and, potentially, drinking water.

Estrogens are steroid hormone-chemicals that are important in human brain, reproduction, and bone development, and are produced by the endocrine system. Estrogens, as well as endocrine disruptive compounds (EDCs; xenoestrogens), are also present in the environment, both from natural sources like plants and fungi, and as by-products of synthetic chemicals. However, in both males and females excess estrogens can cause birth defects, abnormal sexual development, problems with the nervous system and the immune system, and cancer (Rahman et al. 2009; Sumpter and Jobling 1997).

Until now, most of the pollutants that are released and discharged by industry, agriculture and medicine cannot — or can only insufficiently — be removed by conventional techniques and methods of water treatment (Andersen et al. 2003; Ying et al. 2002; Zhang and Zhou 2005). The accumulation of pollutants in soil and water is, therefore, constantly increasing, with problematic substances entering the farm animal and the human food chain. E2 and EE2 are well known for their negative impact on both aquatic life as well as on humans, and are, therefore, already listed as priority substances in a proposal for an amendment of European Directives in the field of water policy (European Commission 2012). However, the overall effects on ecosystems as well as on biochemical pathways are still not fully understood. Recent publications elucidate the effect of estrogens far beyond their generally known scope, such as their involvement in autoimmunity (Chighizola and Meroni 2012), in crosstalk between different estrogen-dependent pathways (Marino et al. 2012), and in epigenetic effects (Wong and Walker 2013).

The elimination of these pollutants requires novel techniques (Silva et al. 2012), as well as an application and implementation of existing technologies from other areas of water treatment, such as membrane adsorption systems. The latter have been applied in the medical field of extracorporeal blood purification with great success. The research activities presented here attempt to apply the know-how gained in the field of blood purification to water technology, in order to gain consolidated findings and improvements with regard to the elimination of problematic substances and pharmaceutical pollutants from drinking water, process/industrial water and wastewater. Therefore, selected adsorbents which are currently available or under development for their use in extracorporeal blood purification were compared with conventional activated carbon regarding their adsorption characteristics for one of the most important native estrogens, namely $17 \beta$-Estradiol (E2), as well as for the synthetic drug $17 \alpha-$ Ethinylestradiol (EE2).

\section{Material and Methods}

\subsection{Batch Tests}

The adsorbents used in the tests (Table 1) offer high surface areas due to a high inner porosity. The experiments for the assessment of the adsorption kinetics were conducted in vitro with $0.01 \mathrm{~g}$ dry adsorbent per $10 \mathrm{~mL}$ aqueous solution $(0.1 \% \mathrm{w} / \mathrm{w})$, spiked with $5 \mu \mathrm{M}$ estrogen in 
Table 1 Adsorbents evaluated for their characteristics to remove E2 and EE2 from water

\begin{tabular}{lll}
\hline Adsorbent & Provider & Characteristics \\
\hline NORIT C Gran & Norit, US & granulated activated carbon \\
NORIT GAC 1240 & Norit, US & granulated activated carbon \\
NORIT Super Cap & Norit, US & powdered activated carbon \\
diaMARS AC 250 & Gambro, Sweden & activated charcoal; $\mathrm{BP}^{\mathrm{a}}$ \\
diaMARS IE 250 & Gambro, Sweden & anion exchanger; $\mathrm{BP}^{\mathrm{a}}$ \\
Prometh01 & Fresenius Medical Care Adsorber Tec GmbH, Austria & neutral resin, BP \\
Prometh 02 & Fresenius Medical Care Adsorber Tec GmbH, Austria & anion exchanger, BP \\
Amberchrom CG300c & Dow Chemical, US & Neutral resin \\
\hline
\end{tabular}

${ }^{\text {a }} \mathrm{BP}$ indicates adsorbers that are commercially used for blood purification

$15 \mathrm{~mL}$ polypropylene tubes (Greiner bio-one, Kremsmünster, Austria). Samples were taken at 10, 20, 30, 60 and $120 \mathrm{~min}$. The estrogens were purchased from Sigma-Aldrich (St. Louis, USA).

For the development of the sorption isotherms, two promising adsorbents (Amberchrom CG300c, Prometh 01) were chosen for batch tests that were conducted, as described above, with different concentrations of EE2. Samples were taken after the adsorption equilibrium was achieved (120 min). To investigate the impact of residual amounts of contaminants in effluent wastewater on their adsorption capacity for estrogens, the sorption isotherms were developed for distilled water as well as for effluent wastewater which was taken from the draining channel of a local sewage plant (Krems, Austria).

\subsection{Estrogen Analysis}

The sample enrichment and purification of estrogens was conducted according to the literature (Alonso et al. 2009) with some minor adaptations. The estrogen-spiked effluent wastewater or ultrapure water was acidified to $\mathrm{pH} 2$ with sulphuric acid. For estrogen enrichment, SPE cartridges were used ( $3 \mathrm{~mL}$ cartridges, $60 \mathrm{mg}$ Oasis HLB; Waters, Massachusetts, USA). The cartridges were conditioned with $3 \mathrm{~mL}$ acetone, $3 \mathrm{~mL}$ methanol, and finally, with 3 mLsulphuric acid $(\mathrm{pH} 2)$. A $150 \mathrm{~mL}$ water sample was pumped through the SPE cartridges at a flow rate of $15 \mathrm{~mL} / \mathrm{min}$ using a roller pump (Ismatec, Wertheim, Germany). After the sample application, it was washed with $3 \mathrm{~mL}$ of methanol/water $(5: 95 \mathrm{v} / \mathrm{v})$. The eluation was performed with two aliquots of $2 \mathrm{~mL}$ acetone at a flow rate of $1 \mathrm{~mL} / \mathrm{min}$ using a syringe pump (KDS 270, Vitaris, Switzerland). The aliquots were dried using a concentrator at $60{ }^{\circ} \mathrm{C}$ (Concentrator 5301, Eppendorf AG, Hamburg, Germany). After the two residues were dissolved in $250 \mu \mathrm{L}$ acetonitrile, they were merged and $20 \mu \mathrm{L}$ were injected into the HPLC column $\left(150 \times 4.6 \mathrm{~mm} \mathrm{C}_{18}\right.$ column contains $5 \mu \mathrm{m}$ particle coupled with a $4 \times 3.0 \mathrm{~mm} \mathrm{C}_{18}$ guard column, Varian $\left.{ }^{\mathrm{TM}}\right)$. The mobile phase for the HPLC analysis was acetonitrile:buffer:water (50:17:33). The buffer was a $30 \mathrm{mM}$ potassium dihydrogen phosphate solution $(\mathrm{pH} 3)$. The flow rate was $1 \mathrm{~mL} / \mathrm{min}$ with a run time of $11 \mathrm{~min}$. Fluorescence detection was performed at an excitation wavelength of $280 \mathrm{~nm}$ and an emission wavelength of $310 \mathrm{~nm}$. The concentrations of E2 and EE2 were calculated on the basis of their peak areas in the HPLC assay. The limit of detection was $0.05 \mu \mathrm{M}$. The analyses were conducted by a Waters HPLC system with a Shimadzu RF-551 fluorescence detector (Harm et al. 2013). 
HPLC-grade acetonitrile, methanol and acetone were purchased from VWR (Pennsylvania, USA). Sulphuric acid and potassium dihydrogen phosphate were obtained from Sigma-Adrich (St. Louis, USA). Ultrapure water was obtained from a reverse osmosis plant (euRO 20 DI, SG, Germany).

\section{Results}

The results for the adsorption kinetics (Fig. 1) as well as the adsorption capacity (Table 2) show that Amberchrom CG300c offers the highest adsorption capacity. However, powdered activated carbon offers the best adsorption kinetics due to its small particle size, and therefore, the very high surface/volume ratio. Prometh 01, a hydrophobic (neutral) resin which is commercially used in extracorporeal liver support for the removal of aromatic amino acids, bile acids and other hydrophobic toxic compounds, shows a promising total capacity as well. However, the adsorption kinetics is much slower due to the larger particle size of $200-800 \mu \mathrm{m}$, and therefore, long diffusion distances for the adsorbate to reach the inner surface of the adsorbent. The same is true for Norit $\mathrm{C}$ Gran. The anion exchanging resin Prometh 02 offers the weakest adsorption characteristics. In contrast, the second anion exchanger, diaMARS IE 250 , shows much better results, most probably due to its smaller particle size and different pore size distribution. Therefore, it can be assumed that the adsorption of estrogens is not based on ionic forces but on hydrophobic interactions to hydrophobic domains of the anion exchanger. Although Norit C GAC 1240 is intended to be used for removal of impurities from water and industrial process applications (Norit Datasheet, No. 2201 2010), it showed, compared to other adsorbents tested in our study, significantly slower adsorption kinetics. However, as shown in Fig. 1, for this adsorbent the equilibrium concentration could not be achieved during the experiment duration of $120 \mathrm{~min}$ and a higher adsorption capacity than shown in Table 2 can be expected.

The sorption isotherms prove that the adsorbent Amberchrom CG300c has an adsorption capacity for EE2 which is, depending on the equilibrium concentration, 10 to 20 times higher

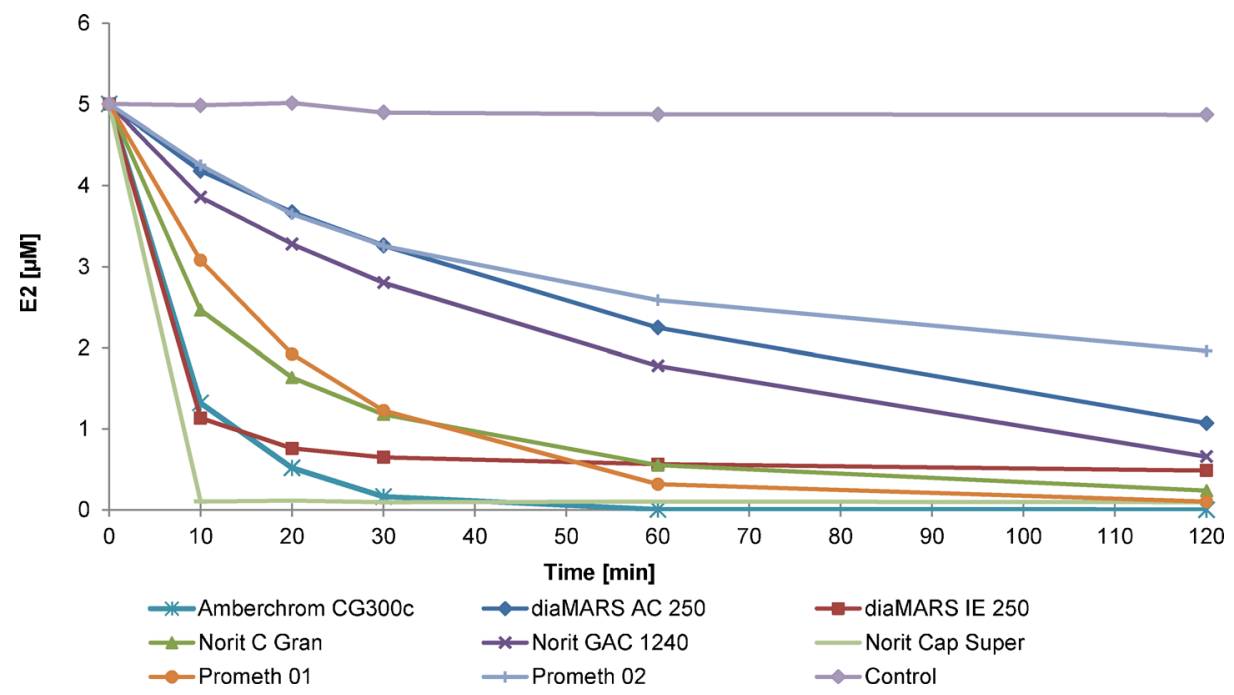

Fig. 1 Adsorption kinetics of the tested adsorbents for E2 in distilled water 
Table $217 \beta$-Estradiol adsorption capacity in distilled water

\begin{tabular}{|c|c|c|}
\hline Adsorbent & Time [min] & Capacity $[\mu \mathrm{g} / \mathrm{g}]$ \\
\hline \multirow[t]{4}{*}{ NORIT C Gran } & 10 & 670 \\
\hline & 20 & 851 \\
\hline & 30 & 889 \\
\hline & 120 & 982 \\
\hline \multirow[t]{4}{*}{ NORIT GAC 1240} & 10 & 261 \\
\hline & 20 & 380 \\
\hline & 30 & 436 \\
\hline & 120 & 781 \\
\hline \multirow[t]{4}{*}{ NORIT Super Cap } & 10 & 1322 \\
\hline & 20 & 1252 \\
\hline & 30 & 1163 \\
\hline & 120 & 1028 \\
\hline \multirow[t]{4}{*}{ diaMARS AC 250} & 10 & 209 \\
\hline & 20 & 322 \\
\hline & 30 & 379 \\
\hline & 120 & 787 \\
\hline \multirow[t]{4}{*}{ diaMARS IE 250} & 10 & 975 \\
\hline & 20 & 1014 \\
\hline & 30 & 962 \\
\hline & 120 & 883 \\
\hline \multirow[t]{4}{*}{ Prometh 01} & 10 & 402 \\
\hline & 20 & 612 \\
\hline & 30 & 690 \\
\hline & 120 & 798 \\
\hline \multirow[t]{4}{*}{ Prometh 02} & 10 & 191 \\
\hline & 20 & 334 \\
\hline & 30 & 383 \\
\hline & 120 & 604 \\
\hline \multirow[t]{4}{*}{ Amberchrom CG300c ${ }^{a}$} & 10 & 1001 \\
\hline & 20 & 1123 \\
\hline & 30 & 1315 \\
\hline & 60 & 1359 \\
\hline
\end{tabular}

than the capacity of Prometh 01 (Fig. 2). In effluent wastewater, the isotherm for EE2 shows a lower adsorption capacity compared to distilled water for the adsorbent Prometh 01 (Fig. 3).

\section{Discussion and Conclusions}

Our results show that both estradiol (E2) as well as $17 \alpha$-ethinylestradiol (EE2) can effectively be removed by adsorption. Especially strongly hydrophobic adsorbents, such as PS-DVB based materials and activated carbon, are the most promising adsorbents for the removal of estrogens. 


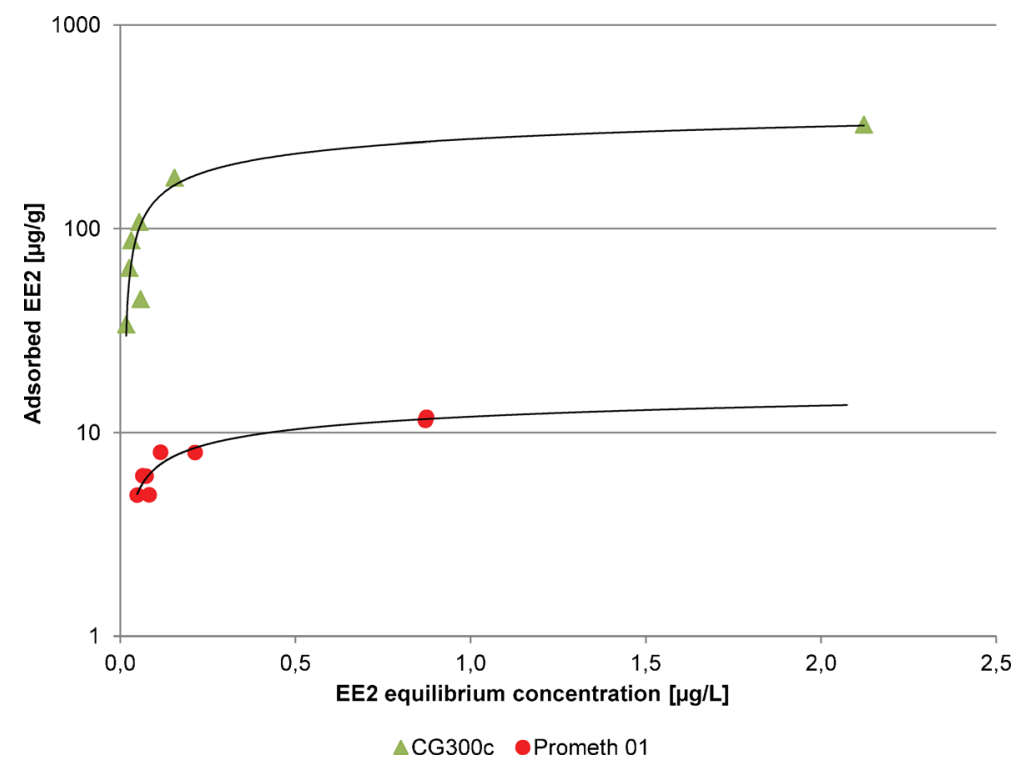

Fig. 2 Sorption isotherm for the adsorbents CG300c and Prometh 01 for EE2 in distilled water

Although the powdered adsorbent offers very good adsorption kinetics as well as adsorption capacity, the practicability of a final upscaled purification system has to be considered. Larger particles and longer contact time between adsorbate and adsorber in order to compensate the longer diffusion distances should be the option of choice.

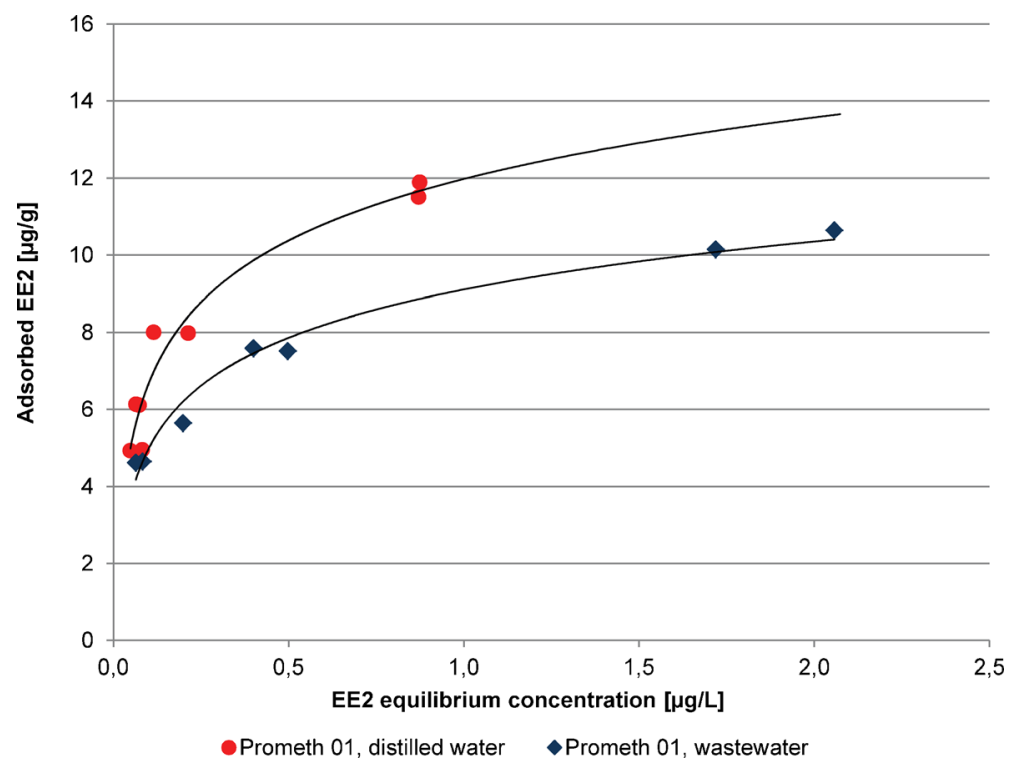

Fig. 3 Sorption isotherm for the adsorbent Prometh 01 for EE2 in distilled water and wastewater 


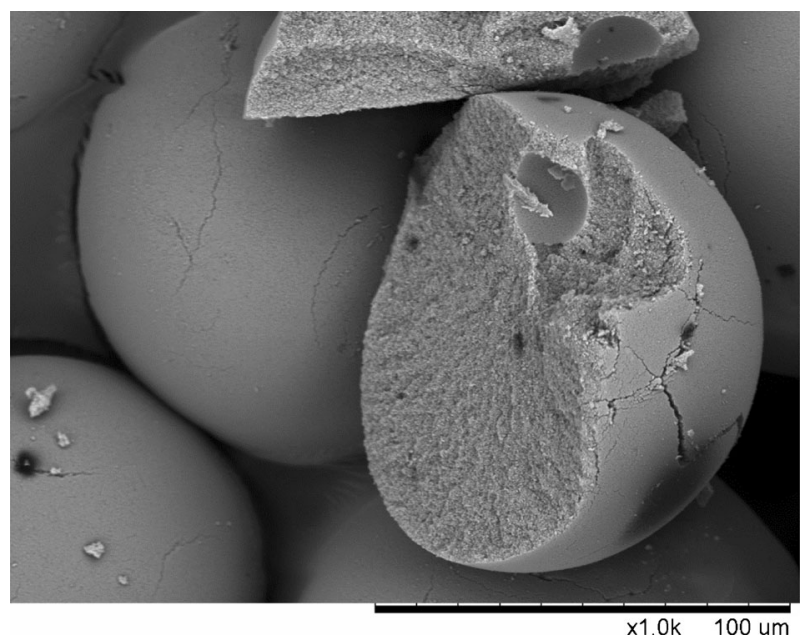

Fig. 4 Scanning electron microscope micrograph of a grinded particle of the adsorbent Amberchrom CG300c

The sorption isotherms show that competitive adsorption lowers the adsorption capacity of the tested adsorbents in effluent wastewater. In order to increase the adsorption capacity of adsorbents in effluent wastewater, larger molecules that reduce the adsorption capacity could be excluded from adsorption either by a membrane or by the adsorbent itself. As an example, Fig. 4 clearly shows the very dense surface layer of the adsorber Amberchrom CG 300c, which serves as a size-selective filter and, therefore, enhances the adsorption capacity of adsorbates with lower molecular weight. The highly porous inner surface of this adsorbent provides a total surface area of 700 sqm per gram adsorber (Rohm and Haas 2006). Furthermore, this optimization of the accessible surface can significantly reduce the desorption of target substances over time caused by competitive adsorption of larger molecules (Vroman effect) (Vilaseca et al. 2013; Vroman 1962).

Further research should be conducted in order to optimize the adsorption capacity as well as to reduce competitive adsorption of other substances, especially when taking into account that the typical concentration of EDCs in surface and groundwater is in the very low range of $<100 \mathrm{ng} / \mathrm{L}$ (Khanal et al. 2006; Zhang and Zhou 2005).

In contrast to other areas where adsorption technologies are applied, such as medical technology, biotechnology and analytical methods, in water technology the amount of needed adsorbent material is high. Nevertheless, purification technology must be kept economical. In order to fulfil this requirement, discarded material from the production process of adsorbents for medical or biotechnological applications could be used for water technology. Furthermore, regeneration cycles could be applied to the adsorbents in order to reuse them as well as to recycle the adsorbed substances after further purification procedures (Asghar et al. 2012).

New technologies are necessary in order to improve or at least to sustain the quality of water. Adsorption technologies or combined membrane-adsorption technologies (Snyder et al. 2007) are, among others such as ozonisation (Snyder et al. 2006), the most promising procedures in order to fulfil this requirement.

Acknowledgments The authors gratefully acknowledge the financial support for this study from the Government of Lower Austria. An initial version of this paper was presented at the 8th International Conference of the EWRA in Porto, Portugal, June 26-29, 2013. 


\section{References}

Alonso E, Camacho-Munnoz D, Martin J, Luis Santos J, Aparicio I (2009) An affordable method for the simultaneous determination of the most studied pharmaceutical compounds as wastewater and surface water pollutants. J Sep Sci 32:3064-3073

Andersen H, Siegrist H, Halling-Sørensen B, Ternes TA (2003) Fate of estrogens in a municipial sewage treatment plant. Environ Sci Technol 37(18):4021-4026

Asghar HMA, Hussain SN, Roberts EPL, Brown NW, Sattar H (2012) Development of composite adsorbent for waste water treatment using adsorption \& electrochemical regeneration. Waset 72:1196-1199

Chighizola C, Meroni PL (2012) The role of environmental estrogens and autoimmunity. Autoimmun Rev 11(6-7):A493-A501

European Commission (2012) Proposal for a directive of the European parliament and the council amending directives 2000/60/EC and 2008/105/EC as regards priority substances in the field of water policy. Brussels COM (2011) 876 final

Harm S, Beyer R, Hartmann J (2013) A new and simple method for simultaneous detection of native and synthetic estrogen. 8th International Conference of EWRA, Porto, Portugal, June 26-29

Khanal SK, Xie B, Thompson ML, Sung S, Ong SK, Van Leeuwent J (2006) Fate, transport, and biodegradation of natural estrogens in the environment and engineered systems. Environ Sci Technol 40(21):6537-6546

Marino M, Pellegrini M, La Rosa P, Acconcia F (2012) Susceptibility of estrogen receptor rapid responses to xenoestrogens: physiological outcomes. Steroids 77:910-917

Norit GAC 1240 (2010) Datasheet, No. 2201, Aug. 2010

Rahman MF, Yanful EK, Jasim SY (2009) Endocrine disrupting compounds (EDCs) and pharmaceuticals and personal care products (PPCPs) in the aquatic environment: implications for the drinking water industry and global environmental health. J Water Health 07(2):224-243

Rohm and Haas (2006) Amberchrom CG300m chromatographic grade resin datasheet

Shannon MA, Bohn PW, Elimelech M, Georgiadis JG, Mariñas BJ, Mayes AM (2008) Science and technology for water purification in the coming decades. Nature 452:301-310

Silva CP, Otero M, Esteves V (2012) Processes for the elimination of estrogenic steroid hormones from water: a Review. Environ Pollut 165:38-58

Snyder SA, Wert EC, Rexing DJ, Zegers RE, Drury DD (2006) Ozone oxidation of endocrine disruptors and pharmaceuticals in surface water and wastewater. Ozone Sci Eng 28:445-460

Snyder SA, Adham S, Redding AM, Cannon FS, DeCarolis J, Oppenheimer J, Wert EC, Yoon Y (2007) Role of membranes and activated carbon in the removal of endocrine disruptors and pharmaceuticals. Desalination 202:156-181

Sumpter JP, Jobling S (1997) Vitellogenesis as a biomarker for estrogenic contamination of the aquatic environment. Environ Health Perspect 103(9):173-178

Vilaseca P, Dawson KA, Franzese G (2013) Understanding and modulating the competitive surface-adsorption of proteins. Soft Matter 9:6978-6985

Vroman L (1962) Effect of adsorbed proteins on the wettability of hydrophilic and hydrophobic solids. Nature 196:476-477

Wong RLY, Walker CL (2013) Molecular pathways: environmental estrogens activate nongenomic signaling to developmentally reprogram the epigenome. Clin Cancer Res 19(14):3732-3737

Ying GG, Kookana RS, Ru YJ (2002) Occurrence and fate of hormone steroids in the environment. Environ Int 28:545-551

Zhang Y, Zhou JL (2005) Removal of estrone and 17 $\beta$-estradiol from water by adsorption. Water Res 39:3991-4003 